\title{
Pharmaceutical Potential of Cerium Oxide Nanoparticles as Anti-Obesity and Anti-Diabetic Nano-Drug
}

\author{
Masoomeh Gholizadeh ${ }^{1}$ and Nouraddin Abdi Goushbolagh ${ }^{2 *}$ \\ ${ }^{1}$ Department of Human Nutrition, Faculty of Medicine, Urmia University of Medical Sciences, Iran \\ ${ }^{2}$ Department of Medical Physics, Faculty of Medicine, shahid sadoughi University of Medical Science, Iran
}

*Corresponding author: Nouraddin Abdi Goushbolagh, Department Medical Physics, Faculty of Medicine, shahid sadoughi University of Medical Science.

Keywords: Cerium oxide nanoparticles; Free Radical; Obesity; Diabetic

\section{Opinion}

Obesity is a universal pathological condition that affected human health seriously. It would be better to say that, treatment methods of obesity have not been effective to date [1]. This problem evoke researchers into a great challenge to overcome it [2]. Broadly speaking, the reactive oxygen species (ROS) play an important role in lipid accumulation [3]. Oxidative stress is an indispensable phenomenon for the adipocyte accumulation [4-6]. Diabetes mellitus (DM) is an endocrine-metabolic disorder that is increasing worldwide due to population aging, urbanization and obesity. Above all, it causes accelerate mortality rate. Increased oxidative stress plays an important role in the development and progression of diabetes and its complications. Diabetes is usually caused by increased production of free radicals or impaired antioxidant defense [7]. Lorcaserin is a serotonin 5-HT2C receptor agonist which imitate from the serotonin effects and causing an increase of satiety and the reduction of the appetite [8]. Qsymia is a combination of the two drugs phentermine and topiramate, which has the role of weight loss by suppressing the appetite and increasing the sense of satiety [9]. It is also worth mentioning that both of these drugs show considerably side effects like dizziness, headache, insomnia, and risk of teratogenicity [10]. Another strategy to decrease body weight is the assumption of dietary polyphenols (such as green tea, resveratrol, curcumin, etc.), that exhibit antioxidant and anti-inflammatory effects related to lipid accumulation [11], but unfortunately, they are rapidly metabolized by enzymes. As a matter of fact they have low stability and bioavailability after the ingestion [12].

Table 1: chemical properties and clinical application of CONPs.

\begin{tabular}{|c|c|c|c|c|c|c|}
\hline Chemical name / Abbreviation & Formula & Molar Mass & Density & $\begin{array}{l}\text { Melting } \\
\text { Point }\end{array}$ & Crystal structure: & Solubility in water \\
\hline $\begin{array}{l}\text { Cerium oxide nanoparticles and nanoceria } \\
\qquad / \text { CONPs }\end{array}$ & $\mathrm{CeO}_{2}$ & $172.115 \mathrm{~g} / \mathrm{mol}$ & $7.22 \mathrm{~g} / \mathrm{cm}^{3}$ & $2,400^{\circ} \mathrm{C}$ & Cubic (fluorite) & Insoluble \\
\hline \multicolumn{6}{|c|}{ Applications } & References \\
\hline \multicolumn{6}{|c|}{ 1. Radioprotector } & $(19-22)$ \\
\hline \multicolumn{6}{|c|}{ 2. Retinal neurodegeneration protection } & 23 \\
\hline \multicolumn{6}{|c|}{ 3. Anti-inflammatory } & 23 \\
\hline \multicolumn{6}{|c|}{ 4. Antioxidant } & $(19,23)$ \\
\hline \multicolumn{6}{|c|}{ 5. Neuroprotective } & 24 \\
\hline
\end{tabular}


Beneficial effects of cerium oxide nanoparticles (CONPs CeO2) or nanoceria cover a wide area of applications, ranging from macular degeneration to cancer therapy which listed in Table 1 [13]. CONPs mimic superoxide dismutase and/or catalase activity, depending on the presence of crystalline defects on their surface (Ce3+/Ce4+ ratio) and the environment $\mathrm{pH}$ where they accumulate [14]. Nanoceria as Reactive Oxygen Species (ROS) scavenger can self-regenerate their antioxidant properties by switch between the two oxidation states of cerium [15]. Thereby cerium oxide nanoparticles could overcome most of the typical limitations of traditional anti-oxidant agents because of the self-regenerating catalytic properties. Conversely to commercially available drugs against obesity, CONPs have useful advantage to strongly scavenge the ROS production for a long-sustained period of time, thus for one thing it reduces the needed doses and eventually diminish the adverse side effects of other drugs [1]. Strategies to reduce the formation of oxidative stress are important in the treatment of DM [16]. It seems that $\mathrm{CeO}_{2}$ nanoparticles as powerful antioxidant with free radical scavenging properties, is suitable for this purpose [17]. CONPs were thought to increase antioxidant power due to their catalytic effect in stimulating superoxide Dismutase (SOD) activity and detoxifying free radicals by staying active in the tissues for a long time through the spontaneously movement between the oxidized and reduced state [18-24]. It was shown in animal model that CONPs could reduce body weight effectively [1]. These promising results may provide a novel treatment in the clinical setting in the future. Bearing in mind that future studies should scrutinize the biocompatibility and bioactivity mechanism of the CONPs in diabetic patients.

\section{References}

1. Rocca A, Moscato S, Ronca F, Nitti S, Mattoli V, Giorgi M, et al. (2015) Pilot in vivo investigation of cerium oxide nanoparticles as a novel antiobesity pharmaceutical formulation. Nanomedicine 11(7): 1725-1734.

2. De Jong AJ, Kloppenburg M, Toes RE, Ioan-Facsinay A (2014) Fatty acids, lipid mediators, and T-cell function. Frontiers in immunology 5: 483.

3. Skalicky J, Muzakova V, Kandar R, Meloun M, Rousar T (2009) Oxidative stress and metabolic syndrome in obese adults with and without controlled diet restriction. Bratislavske lekarske listy 110(3): 152-157.

4. Furukawa S, Fujita T, Shimabukuro M, Iwaki M, Yamada Y, et al. (2017) Increased oxidative stress in obesity and its impact on metabolic syndrome. The Journal of clinical investigation 114(12): 1752-1761.

5. Pires KM, Ilkun O, Valente M, Boudina S (2014) Treatment with a SOD mimetic reduces visceral adiposity, adipocyte death, and adipose tissue inflammation in high fat-fed mice. Obesity 22(1): 178-187.

6. Shrivastava A, Chaturvedi U, Singh SV, Saxena JK, Bhatia G (2013) Lipid lowering and antioxidant effect of miglitol in triton treated hyperlipidemic and high fat diet induced obese rats. Lipids 48(6): $597-$ 607.

7. Rahimi R, Nikfar S, Larijani B, Abdollahi M (2005) A review on the role of antioxidants in the management of diabetes and its complications. Biomedicine \& Pharmacotherapy 59(7): 365-373.
8. Gallwitz B (2013) Novel oral anti-obesity agents: New perspectives with lorcaserin? Drugs 73(5): 393-395.

9. Kim GW, Lin JE, Blomain ES, Waldman SA (2014) Antiobesity pharmacotherapy: New drugs and emerging targets. Clinical Pharmacology \& Therapeutics 95(1): 53-66.

10. Adan RA (2013) Mechanisms underlying current and future anti-obesity drugs. Trends in neurosciences 36(2): 133-140.

11. Meydani M, Hasan ST (2010) Dietary polyphenols and obesity. Nutrients 2(7): 737-751.

12. Wang S, Moustaid-Moussa N, Chen L, Mo H, Shastri A, et al. (2014) Novel insights of dietary polyphenols and obesity. The Journal of nutritional biochemistry 25(1): 1-18.

13. Caputo F, De Nicola M, Ghibelli L (2014) Pharmacological potential of bioactive engineered nanomaterials. Biochemical pharmacology 92(1): 112-130.

14. Das S, Dowding JM, Klump KE, McGinnis JF, Self W, et al. (2013) Cerium oxide nanoparticles: applications and prospects in nanomedicine. Nanomedicine 8(9): 1483-1508.

15. Karakoti A, Singh S, Dowding JM, Seal S, Self WT (2010) Redox-active radical scavenging nanomaterials. Chemical Society Reviews 39(11): 4422-432

16. Naso D, Cangeri F, Simões Dias A, Porawski M, Marroni NAP (2011) Exogenous superoxide dismutase: Action on liver oxidative stress in animals with streptozotocin-induced diabetes. Experimental diabetes research.

17. Pourkhalili N, Hosseini A, Nili-Ahmadabadi A, Hassani S, Pakzad M, et al. (2011) Biochemical and cellular evidence of the benefit of a combination of cerium oxide nanoparticles and selenium to diabetic rats. World journal of diabetes 2(11): 204-210.

18. Andreescu ES, Leiter JC, Erlichman JS (2010) Method of neuroprotection from oxidant injury using metal oxide nanoparticles. Google Patents.

19. Abdi Goushbolagh N, Abedi Firouzjah R, Ebrahimnejad Gorji K, Khosravanipour M, Moradi S, et al. (2018) Estimation of radiation dose-reduction factor for cerium oxide nanoparticles in MRC-5 human lung fibroblastic cells and MCF-7 breast-cancer cells. Artificial cells, nanomedicine, and biotechnology 46(sup3): 1215-1225.

20. Abdi Goushbolagh N, Astani A (2018) In-vitro study of Radioprotection Effects of Cerium Oxide Nanoparticles in Exposure to MRC-5 Fibroblastic Cell lines with 6MV Photon Beams Using MTT Assay. Iranian Journal of Medical Physics 15(12): 397.

21. Nouraddin Abdi Goushbolagh, Akram Astani, Mohammad hosein Zare (2018) Optimization of condition for Cerium Oxide Nanoparticles dispersion as radioprotective agent in deionized water. Iranian Journal of Medical Physics 15(12): 397.

22. Goushbolagh NA, Farhood B, Astani A, Nikfarjam A, Kalantari M, et al. (2018) Quantitative cytotoxicity, cellular uptake and radioprotection effect of cerium oxide nanoparticles in MRC-5 normal cells and MCF-7 cancerous cells. BioNanoScience 8(3): 769-777.

23. Wang C, Blough E, Dai X, Olajide O, Driscoll H, et al. (2016) Protective effects of cerium oxide nanoparticles on MC3T3-E1 osteoblastic cells exposed to X-ray irradiation. Cellular Physiology and Biochemistry 38(4): 1510-1519.

24. Schubert D, Dargusch R, Raitano J, Chan SW (2006) Cerium and yttrium oxide nanoparticles are neuroprotective. Biochemical and biophysical research communications 342(1): 86-91. 
(C) This work is licensed under Creative To Submit Your Article Click Here:

Submit Article

DOI: $10.32474 / A D 0.2019 .02 .000139$

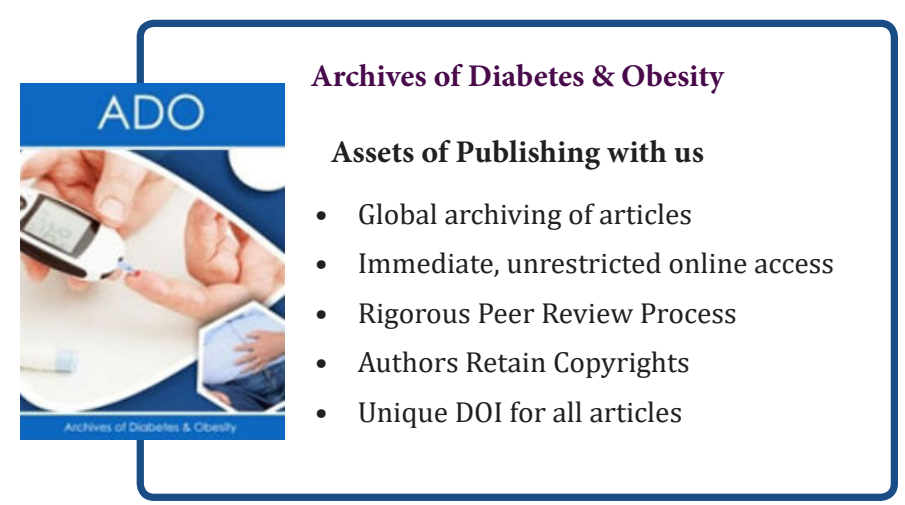

